\title{
The use of appreciative inquiry as an interview technique in radiography research
}

\author{
K Naidoo, DTech: Radiography
}

Department of Medical Imaging and Therapeutic Sciences, Faculty of Health and Wellness Science, Cape Peninsula University of Technology, Cape Town, South Africa

Corresponding author: KNaidoo (naidooka@cput.ac.za)

\section{Why was the idea necessary?}

The use of appreciative inquiry (AI) formed the basis of the interview questions for a study that focused on exploring and understanding the concept of caring among first-year radiography students to develop a model to teach caring. The aim was that the participants should collaborate by sharing their understandings, without it merely being a session for complaining. When participants are asked questions in a positive manner, they are more willing to engage and share their stories. AI is a method of focusing on the positive in any situation to create innovative ideas that bring about more meaningful, deeper and sustainable change. ${ }^{[1,2]}$ While the use of AI is increasing, I have not found any research using this tool among diagnostic radiography students.

\section{What was tried?}

The 4-D model of AI, i.e. Discovery, Dream, Design and Destiny (Fig. 1), has been used extensively in AI research; it was also used to structure the questions in the focus group interviews in this study. Questions in these interviews were asked in a positive manner to promote storytelling that provided narrative-rich communication.

Firstly, participants were asked to share stories where they Discovered a time or times when they expressed or experienced caring. It also made them focus on a time that caring meant the most to them. The following question was posed to participants: 'Tell me what caring means to you as a student radiographer.'

Secondly, participants were asked to share stories where they were given the opportunity to Dream about the ideal caring professional. The following question was asked: 'Describe how you see yourself in the future as a caring radiographer'

Next, participants were asked to Design and create the qualities and attributes required by them to become the ideal caring professional. The question asked was: 'What do you think you will need to be a caring radiographer?'

Lastly, there was the Destiny phase, where participants were asked to develop innovative ways to achieve the required qualities and attributes of a caring professional. The question was: 'Tell me creative/innovative ways in which we can achieve this caring.'

\section{What were the lessons learnt?}

$\mathrm{AI}$ is an effective interview tool, as it allowed for collaboration and teamwork. Using this technique, participants were very eager and willing to share their experiences. This method also promoted a very comfortable environment for storytelling among participants. Rich and informative data were collected. The use of AI in radiography research has proved to be valuable. $\mathrm{AI}$ is an innovative method that allows healthcare professionals to

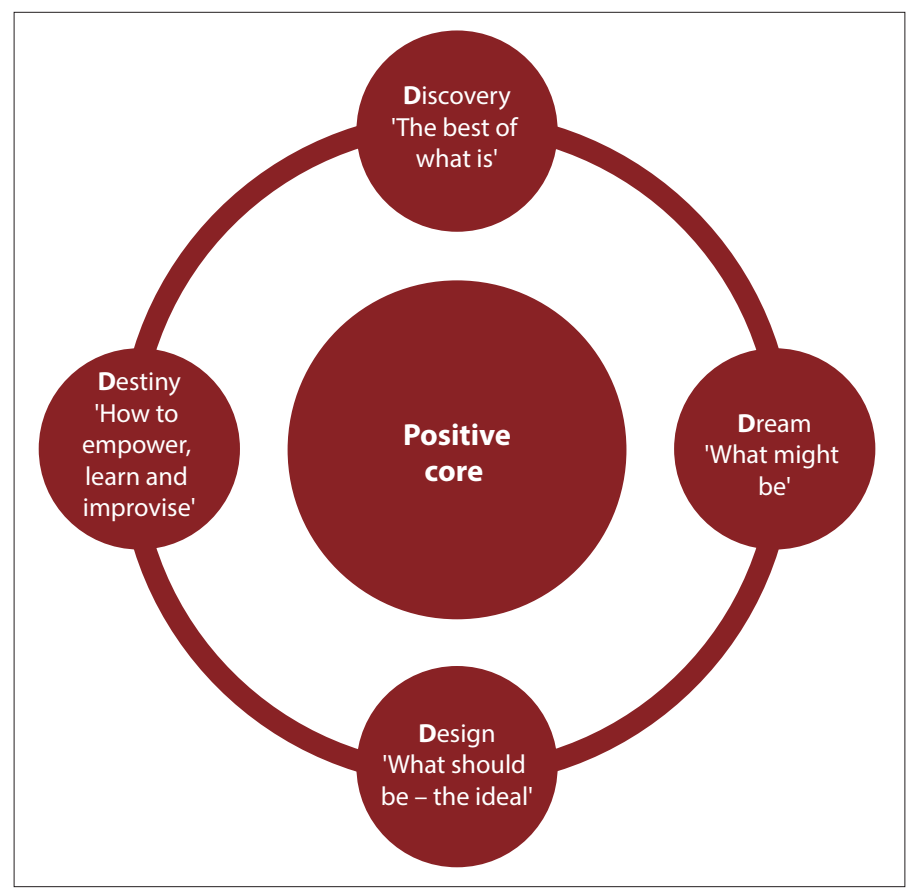

Fig. 1. The 4-D model of appreciative inquiry. ${ }^{[1]}$

explore the potential of change by moving the focus away from the problems at hand.

Declaration. None.

Acknowledgements. The author thanks all participants for their valuable contribution to the study.

Author contributions. Sole author.

Funding. The researcher would like to thank the Health and Welfare Sector Education and Training Authority (HWSETA) for providing funding for this study (postgraduate research bursaries 2017 - 2018).

Conflicts of interest. None.

1. Cooperrider D. What is appreciative inquiry? 2012. http://www.davidcooperrider.Com/Ai-Process/ (accessed 4 March 2020)

2. Richer MC, Ritchie J, Marchionni C. 'If we can't do more, let's do it differently!' Using appreciative inquiry to promote innovative ideas for better health care work environments. J Nurs Manage 2009;17(8):947-955. https:// doi.org/10.1111/J.1365-2834.2009.01022.X

Accepted 19 November 2019

Afr J Health Professions Educ 2020;12(2):51. https://doi.org/10.7196/AJHPE.2020.v12i2.1269 